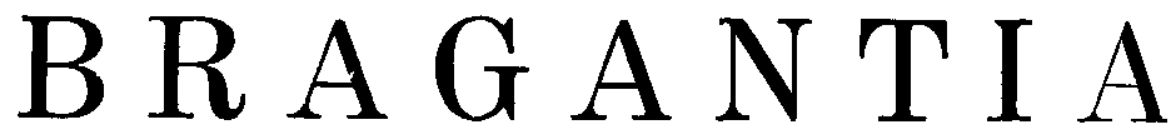

Boletim Técnico do Instituto Agronômico do Estado de São Paulc

Vol. 17

Campinas, dezembro de 1958

N.० 18

\title{
DISPOSIÇÃO DAS MUDAS DE CAFÉ NA COVA (*)
}

J. E. TelxeIra Mendes, engenheiro-agrônomo, Divisão de Agronomia e H. J. Scaranari, engenheiro-agrônomo, Seção de Genética, Instituto Agronômico

\section{RESUMO}

No presente trabalho sāo apresentados os dados de produção de cafeeiros plantados a quatro mudas por cova, variando, contudo, a maneira de sua distribuição dentro do cova. Um dos tratamentos corresponde ao sistema comum de plantio, no qual as mudas são dispostas em quadrado, na cova. $O$ outro refere-se à disposição das quatro mudas em linha na cova. Visava-se, plantando as mudas desta última forma, facilitar o combate à broca do café pela retirada dos grāos que normalmente caem e ficam presos no centro dos quatro troncos formados pelo sistema comum. Os resultados obtidos, correspondentes ao período de 1951 a 1956, nāo indicaram diferenças significativas entre as produçōes dos dois trotamentos. Desta forma, embora o problema do combate à broca do café esteja resolvido com o emprêgo de inseticidas modernos, os resultados dêste ensaio mostram que qualquer um dos sistemas de plantio pode ser adotado no estabelecimento de cafèzais.

\section{1 - INTRODUÇÃO}

Durante longos anos debateu-se a lavoura cafeeira com o problema do combate ao inseto que tantos prejuizos causou à economia nacional. Trata-se da broca do café Hypothenemus hampei (Ferr.). Uma vez constatada sua ação destruidora dos grãos de café, as instituições de pesquisas passaram a estudar a sua biologia e os meios para combater o inseto, chegando à conclusão de que a colheita cuidadosa e uma varrição esmerada eram os meios mais eficazes ao seu combate (1). Isto porque a maneira usual da broca sobreviver no período da entre-safra é hospedar-se nos frutos de café que não foram recolhidos, isto é, que permaneceram no chão ou presos entre os ramos do cafeeiro. Uma vez inteiramente eliminados êstes grãos, a colheita seguinte estaria pròticamente livre da praga.

O sistema de plantio de café comumente empregado na formação das antigas lavouras tem constituído, de certa forma, um empecilho

(*) Recebido para publicaçăo em 14 de março de 1958. 
à boa catação dos frutos. A semeação direta na cova, feito sem cuidados para que haja uma boa distribuição das mudas formadas, contribui para que os grãos de café caídos entre os troncos dos cafeeiros dificilmente possam ser retirados, servindo para garantir à broca meios para sobreviver. Igualmente, o emprêgo de jacàzinhos para embalagem de quatro mudas destinadas às replantas ou às novas plantaçōes também contribui para que entre os quatro troncos dos cafeeiros formados permaneçam alguns frutos caídos, impossibilitando, assim, a limpeza preconizada no combate profilático à broca do café. Surgiu então a idéia de se plantar em linha, dentro da cova, as quatro mudas de café, ao invés de sua disposição em quadrado, comumente usada. Nessa ocasião já existiam no comércio os recipientes de madeira laminada para embalagem de mudas individuais, facilitando, desta maneira, tal disposição das mudas. Plantando-se o cafeeiro de acôrdo com o novo sistema, possibilitar-se-ia uma limpeza mais fácil e perfeita e, conseqüentemente, a eliminação dos grãos que pudessem hospedar a broca no período de entre-safra.

É certo que hoje em dia o aplicação de inseticidas à base de $\mathrm{BHC}$ (hexacloreto de benzeno) se mostrou eficaz de modo a reduzir os efeitos da broca do café $(3,4)$. Dêste modo a disposição das mudas em linha passou a interessar apenas como um sistema diferente de plantio. Quando, porém, o ensaio foi instalado, achava-se em sua fase inicial o combate ò broca do café por meio de inseticidas. Os resultados obtidos e apresentados no presente trabalho servem, no entanto, para estabelecer uma comparação entre o método comum de disposição dos cafeeiros na cova com a disposição em linha, também na cova. Conquanto não muito comum, esta prática se encontra em algumas lavouras do Estado de São Paulo.

\section{2 - MATERIAL E MÉTODO}

$O$ ensaio para estudar os dois sistemas de plantio foi instalado na Estação Experimental Central, em Campinas, em solo tipo terraroxa-misturada. As mudas de cafeeiros da variedade bourbon vermelho (Coffea arabica L. var. bourbon (B. Rodr.) Choussy) foram obtidas a partir da semeação em viveiro. Cêrca de cinco meses após essa semeação, as mudas foram transplantadas de canteiros para recipientes de lâmina de madeira e plantadas no local definitivo em dezembro de 1948, a quatro mudas por cova. Estas foram abertas com $60 \times 60 \times 50 \mathrm{~cm}$ 
de dimensões e foram adubadas com 10 quilos de estêrco, $300 \mathrm{~g}$ de farinha de ossos, $100 \mathrm{~g}$ de cloreto de potássio e $100 \mathrm{~g}$ de salitre do Chile.

O ensaio compreende dois tratamentos referentes ao plantio, nas covas, de: a) quatro mudas em linha; b) quatro mudas em quadrado. As mudas em linha foram dispostas na parte central da cova e separadas de $15 \mathrm{~cm}$; no plantio em quadrado a distância entre mudas foi de $30 \mathrm{~cm}$. O plano adotado foi o de blocos ao acaso com 20 repetições, sendo cada repetição formada por uma única cova de café. Foi plantada uma linha de bordadura geral externa. A distância entre covas foi de $2,70 \times 2,70 \mathrm{~m}$.

\section{3 - RESULTADOS OBTIDOS}

\section{1 - PRODUÇÃO}

Os cafeeiros entraram em produção em 1951. Fêz-se a colheita sòmente dos frutos maduros, em duas vêzes, com exceção dos anos de 1951 e 1956, quando todos os frutos foram colhidos numa única colheita. Após secagem no terreiro, o café em côco obtido foi pesado, tomando-se êsse pêso para análise das produções. Os dados do quadro I mostram as produções anuais dos cafeeiros nas diferentes repetições, no período de 1951 a 1956. Pode-se observar que as diferenças de produção entre os tratamentos são pequenas em todos os anos em estudo. A análise da variância é a seguinte e indica não haver diferença significativa entre os tratamentos.

\begin{tabular}{|c|c|c|c|c|}
\hline Fontes de variação & SQ & $G L$ & $Q M$ & $\mathrm{~F}$ \\
\hline Blocos $\quad \ldots . . .$. & 19,9663 & 38 & 0,5254 & \\
\hline Tratamentos & 0,0543 & 1 & 0,0543 & $0,44 \mathrm{~ns}$ \\
\hline Anos & 36,6293 & 5 & 7,3258 & \\
\hline Int. $(\operatorname{Tr} . \times A)$ & 0,4535 & 5 & 0,0907 & \\
\hline Êrro & 23,3809 & 190 & 0,1230 & \\
\hline Total & 80,4843 & 239 & & \\
\hline
\end{tabular}

Embora seja elevada a variação devida a anos para os dois sistemas de disposição das mudas, não se nota, contudo, efeito significativo da interação entre tratamentos e anos. 


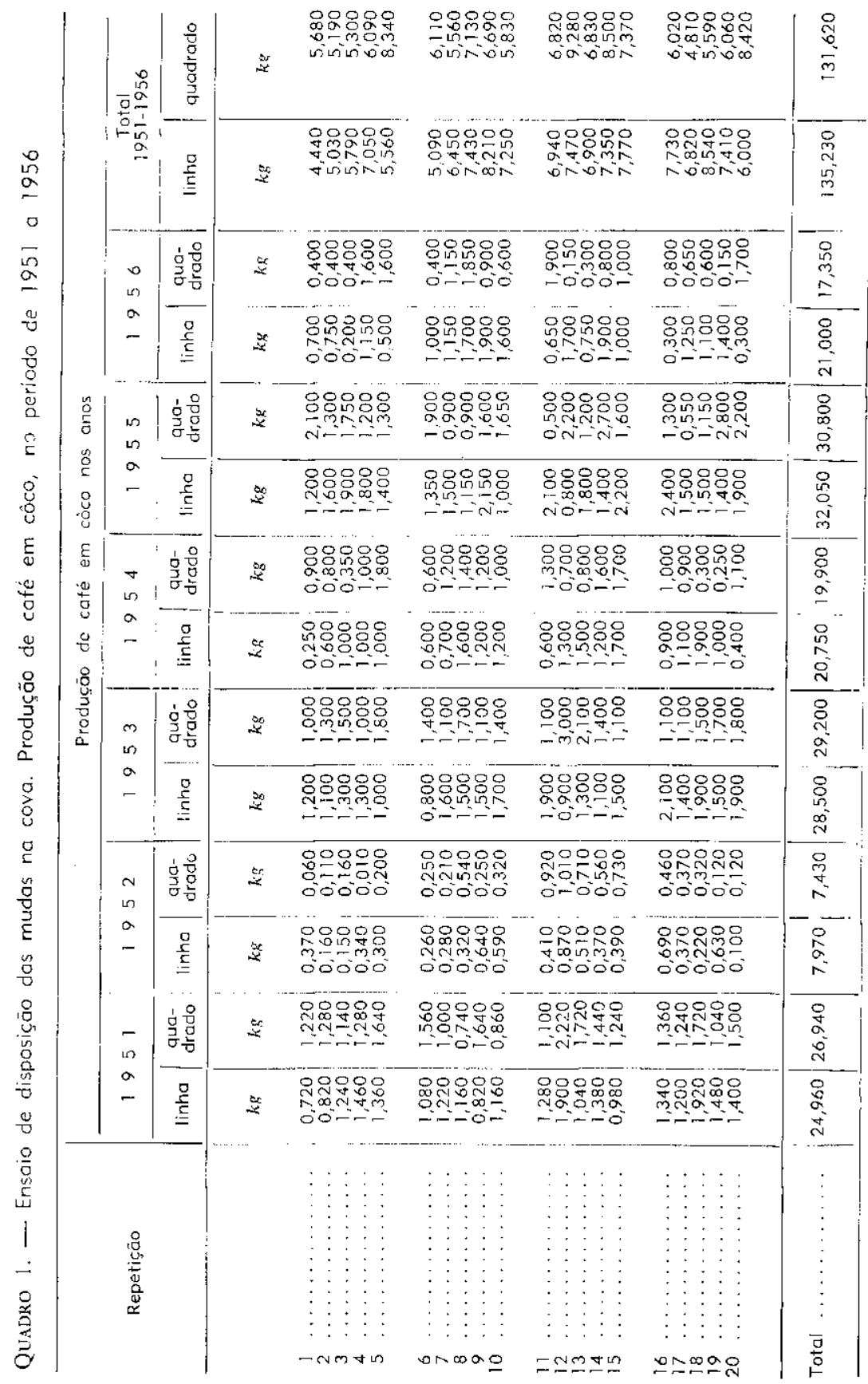




\section{2 - TAMANHO DAS SEMENTES}

A determinação da peneira média (2), foi feita para os tratamentos em estudo, nos anos de 1952 a 1956; tomou-se em cada um dos anos uma amostra média do café em côco obtido das 20 repetições, a qual foi beneficiada para tal fim. No quadro 2 podem-se observar

Quadro 2. - Ensaio de disposição das mudas na cova. Peneira média do café beneficiado, nos anos de 1952 a 1956

\begin{tabular}{|c|c|c|c|c|c|c|}
\hline \multirow{2}{*}{$\begin{array}{l}\text { Disposição das } \\
\text { mudas na cova }\end{array}$} & \multicolumn{5}{|c|}{ Peneira médio } & \multirow{2}{*}{ Média } \\
\hline & 1952 & 1953 & 1954 & 1955 & 1956 & \\
\hline Em linha ..................... & 16,58 & 15,90 & 16,24 & 16,01 & 15,34 & 16,01 \\
\hline Em quadrado ......... & 16,52 & 15,74 & 16,28 & 15,88 & 15,56 & 16,00 \\
\hline
\end{tabular}

os dados obtidos. Verifica-se que as diferenças entre as peneiras médias do café colhido nos dois tratamentos são pequenas, indicando, assim, não haver influência, no tamanho das sementes, da maneira de distribuir as mudas na cova.

\section{4 - DISCUSSĀO E CONCLUSÕES}

O presente ensaio foi iniciado quando os primeiros resultados obtidos com o emprêgo do BHC no combate à broca estavam sendo fomentados. Naquela ocasião a possibilidade de se fazer uma melhor limpeza embaixo do conjunto de cafeeiros que formam o que se denomina em São Paulo "pé de café", constituia importante fator na manutenção das lavouras em boas condições, com relação ao combate àquela praga.

Ao darmos à publicidade os dados dêste ensaio, modificou-se totalmente o problema do combate à broca com o emprêgo de inseticidas.

No entanto, o ensaio serviu para demonstrar que o plantıo dos cafeeiros em quadrado ou alinhados, na cova, produz idênticos resultados, podendo ser adotado indistintamente, desde que qualquer um dêles apresente no momento ou no local qualquer facilidade de execução. 


\section{COFFEE SEEDLING PLACEMENT IN THE PLANTING HOLE}

\section{SUMMARY}

Individual trees in coffee plantations established in the state of São Paulo usually result from four seedlings that were placed in a square within the planting hole. When the plants begin to bear, this planting system favors the coffee berry-borer infestation because many fruits fall in between the stems of the four plants and are hard to be collected, thus remoining as a food source for the insect between two successive crops.

Placing the seedlings in a straight line within the planting hole was thought as a method that would facilitate the harvest and permit the collection of fruits left bchind on the trees or near their trunks. An experiment designed to compare this planting method with the usual one wos undertaken at the Central Experiment Station, Instituto Agronômico, Campinas. The Red Bourbon variety of Coffeca arabica was used. The seedlings in line were placed $15 \mathrm{~cm}$ apart, and at about $30 \mathrm{~cm}$ when in a square. A randomized block design with 20 replications for the two treatments was used, cach plot comprising a single hole with four seedlings.

Yield records were taken for the years 1951 through 1956 (Table 1). The size of the beans was also studied (Table 2). The total yield in dried fruit for this period was $135.2 \mathrm{~kg}$ for the plots with the seedlings in line and $131.6 \mathrm{~kg}$ for those with seedlings planted in a square. The difference between the two treatments was not significant. Large differences were observed between years for the some treatment, but the interaction treatments $x$ years was not significant.

Today the control of the coffee berry-borer is efficiently corried out by dusting or spraying $\mathrm{BHC}$ on the trees; the method of placing the seedlings in a line within the planting hole does not present advantages anymore. The results here discussed indicate, however, that both methods of seedling placement in the planting hole can be used by the farmers without affecting the yield.

\section{LITERATURA CITADA}

1. FONSECA, J. PINTO \& AUTUORI, M. Principais pragas do café no Estado de São Paulo. São Paulo, Inșt. Biol. Def. Agric. e Anim., Divisão Vegetal, 1932. $87 \mathrm{p}$.

2. KRUG, C. A. O cálculo da peneira médio na seleção do cafeeiro. Rev. Inst. Café 15:123-127. 1940.

3. SEIXAS, C. A. Contrôle químico da broca do café. Biológico 13:2:15-228. 1947.

4. A prática do combate quimico à broca do café. Biológico 14:71-89. 